\title{
Mixing Problem Based Learning And Conventional Teaching Methods In An Analog Electronics Course
}

J. M. Podges, Walter Sisulu University of Technology, South Africa P.A.M. Kommers, University of Twente, The Netherlands K. Winnips, Groningen State University, The Netherlands W.R van Joolingen, Utrecht University, The Netherlands

\begin{abstract}
This study, undertaken at the Walter Sisulu University of Technology (WSU) in South Africa, describes how problem-based learning (PBL) affects the first year 'analog electronics course', when PBL and the lecturing mode is compared. Problems were designed to match real-life situations. Data between the experimental group and the control group that related to attitudinal effect; the amount of reflection and learning outcome effects, were compared. A strong correlation was found between the students' attitudes and project marks for those who used the problem-based learning method. It was found that students who followed the PBL method learned to do research, learned better how to work in groups and developed greater confidence. Also what they learned was more of a practical value and they had more positive attitudes and reflected more, but there were no significant improvements in their learning. This research is in response to the real need to address gaps between employer expectations and higher education outcomes in South Africa.
\end{abstract}

Keywords: PBL; Problem-Solving; Engineering Education; Electronics Practical

\section{INTRODUCTION}

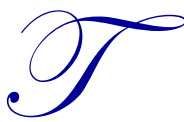

raditionally, engineering students have to do laboratory (lab) experiments as part of the curriculum and they should be able to apply their knowledge. According to Kitogo (2011), "today's graduates have attractive curricula vitae, but practically, their performance is insufficient; it doesn't match with what they claim to have studied". According to Case (2011), students in the lecturing mode who followed the traditional instruction are graduating with a good knowledge of fundamental engineering science and computer literacy, but they do not know how to apply that in practice. Students tend to memorize new information instead of using it as a tool to solve problems when it is presented to them without meaning or relevance in the lecturing mode and this leads to inert knowledge (Whitehead, 1929).

Employers expect more from local graduates, especially when it comes to the application of knowledge (Griesel \& Parker, 2009). According to Erasmus, Loedolff, Mda, and Nel (2006), young people are unemployed or lack entrepreneurship due to a lack of specialized skills. Some of those skills are identified by Bethlehem (1997) as 'communication skills', 'decision-making skills', 'analytical skills', teamwork skills, 'well-practised leadership skills' and 'good interpersonal skills'. Many students at WSU struggle to design an electronic project of reasonable proportion in a final year programme under the label 'Design Projects 3' due to a lack of application of knowledge.

Problem-Based Learning (PBL), an alternative to the traditional lecture-based approach, is built on the principle of constructivism in which learners are confronted with a meaningful authentic context. PBL originated from the McMasters University in Canada in the late sixties, using a problem-based approach in medicine (Kolmos, de Graaff, \& DU, 2009). Some European universities such as Aalborg in Denmark also implemented problem orientated, project organised PBL (Kolmos, Fink, \& Krogh, 2006). Problem analysis, participation in two or more 
fields of study and sharing of activities in group work is common amongst the McMasters and Aalborg models, but they differ with regards to assignments, assessment and group work (de Graaff \& Kolmos, 2003).

Barrows identified the following varieties of PBL in 1986: Lecture-based cases, case-based lectures, case methods, modified case-base method, problem-based learning and closed loop problem-based learning (Kolmos et al., 2009). The following five different models were proposed by Savin-Baden (2007) as cited in Kolmos et al. 2009: Attainment of knowledge, PBL for professional work, PBL for interdisciplinary understanding, PBL for crossdiscipline learning and PBL for critical competencies. When solving authentic PBL problems, learners need to explore the concepts, find resources and apply the knowledge. (Boud \& Feletti, 1997; Ornstein \& Hunkins, 1993) The students' attitudes towards subject matter domains can be positively affected when using PBL (Bridges \& Hallinger, 1991; Pincus, 1995). Dusick (1998, pp. 123-137) defined attitude as "an evaluative disposition based upon cognition, effective reactions, behavior intentions, and past behaviors which can influence future cognitions, effective responses, intentions, and behaviors". Students enjoy the learning process while in the PBL mode and they develop a positive attitude towards the instructional environment. This is in contrast to students in the lecturing mode, who find the traditional methods boring and irrelevant (Schmidt, Lipkin, de Vries, \& Greep, 1989). Students who enjoy a successful learning experience may have a better learning attitude according to Hwang and Kim (2006).

Problems are at the very heart of the PBL paradigm, and reflection is critical to PBL. Schön (1983) mentioned that when you reflect on action, you need to think back on what you have done in order to discover how your knowing-in-action may have contributed to an unexpected outcome. Reflection is a mental process of thinking and learning often used in everyday life. Giving students the opportunity to evaluate and reflect on their own learning is a key element in PBL. Once finished, students can reflect to see if they have reached the initial goal set at the beginning of the project. They take responsibility for their own learning and the process guides them towards the goal of becoming life-long learners (Waters \& McCracken, 1997). When solving the PBL problems, the students have to solve genuine problems, as they happen in the real world, and this allows them to develop "deeper and richer knowledge structures, leading to a higher likelihood of transfer to novel situations" (Albanese \& Mitchell, 1993, pp. 52-81). While participating in peer groups, student contributions may result in a difference of ideas and perspectives which may need some reasoning, thus leading to the refinement of their knowledge (Grabinger, Dunlap, \& Duffield, 1995). Prince (2004) also refers to the more positive attitudes, but found a deeper approach to learning and a longer retention period with the PBL students compared to their conventional counterparts.

"There are massive disparities in performance between schools within the South African system, to a large extent structured by a history of poverty and deprivation, with African schools overwhelmingly represented in the poor performing category" (Taylor, 2008, p. 3). Many students who study at WSU come from these "African schools' and it is expected that PBL will contribute towards their skills development, especially critical thinking and design skills. PBL was introduced in the Electronics 1 course, one of the major subjects for 1st year electrical engineering students at WSU. Like O' Kelly (2005), our chosen approach is also based on the work of Woods (1996), who advises to start at a comfortable place, achievable within the infrastructure of the institution. In this article, the influence of PBL on a first year analog electronics course is analyzed. Its main objective is to determine how the learning process of students is affected when both traditional teaching methods and PBL teaching methods is used in a mixed way.

\section{Research Questions}

1. What attitudinal effects can be attributed to PBL compared to the lecturing mode?

2. Does PBL increase the amount of reflection by the student?

3. What learning outcome effects can be attributed to PBL compared to the lecturing mode?

\section{Independent variable}

The independent variable for the research study was the instructional strategy. The first level of the independent variable is the PBL strategy. The second level of the independent variable is the traditional, lecturebased instructional strategy. 


\section{Hypotheses}

The research questions address the effect of PBL on the attitude, reflection and academic performance of the two groups of students in the study: the group of students that received traditional instruction (CG) versus the group that received PBL instruction (EG). The following three hypotheses were developed based on the three research questions.

1. It is hypothesized that the overall attitude towards the learning required to design electronic circuits will be more positive among students who participate in PBL activities compared to those in the lecturing mode.

2. It is hypothesized that the amount of reflection will be higher among the students who participate in the PBL mode compared to those in the lecturing mode.

3. It is hypothesized that the level of near transfer skills and the retention knowledge will be higher among students who participate in PBL activities compared to those in the lecturing mode. (Far transfer skills will not be tested during this study.)

\section{EXPERIMENTAL SETUP}

The process and purpose of the research study was explained to the existing Electronics 1 semester-based class of 44 students at WSU, College Street campus and all of them agreed to participate. The 44 students were allocated randomly to one of the two conditions: EG: Experimental Group (with the PBL instruction) and the CG: Control Group (in the traditional lecturing mode). In both conditions the students were randomly grouped in dyads (pairs) instead of larger groups by the lecturer due to the low student numbers and simplicity of the PBL problem. All students were satisfied with the allocations made and no one requested to change groups or partners. One student left the course early in the semester, leaving the EG group with only 21 students. According to Yusof, Hassan, and Tasir (2007, p. 115), "most students who enter the university come from a traditional, plenary educational system and many of them are not ready for the change to university life, much less for PBL". PBL requires students to work much harder and was used with the EG only to cover certain parts of the course.

This research focuses on the selection of a special type of project-based lab activity suitable for students in their first year, given the lack of technical knowledge, and which would still offer students the opportunity to work on real-life engineering projects and gain and practise skills in wiring and testing electrical circuits, the proper use of electronic instruments and the interface of various components, similar to those of Nedic, Nafalski, and Machotka (2010). The PBL classes were based on the traditional Aalborg model which is founded on problem-based project work according to Kolmos et al. (2006), and which means to solve real-life problems that students may face in their future jobs. Table 1 shows the activities around the experiment. The EG participated in the PBL activities during weeks $9-13$ of the mixed semester course.

Table 1. Activities During Semester

\begin{tabular}{cll}
\hline Week & \multicolumn{1}{c}{ EG (Experimental Group) } & \multicolumn{1}{c}{ Activities } \\
\hline & \multicolumn{1}{c}{ CG (Control Group) } \\
\hline 9 & Pre-Test 1 (paper test) & Pre-Test 1 (paper test) \\
9 & Traditional theory (portion of module 5) & Traditional theory (portion of module 5) \\
$9-10$ & Experiment: PBL and Lab instruments & Traditional theory (remainder of module 5) \\
$11-13$ & Experiment: PBL and Lab instruments & Experiment: Traditional way and Lab instruments \\
$12-13$ & Traditional theory (modules 6,7 and portion of 8) & Traditional theory (modules 6,7 and portion of 8) \\
14 & Post-Test 1, Attitude 1, Reflection 1 Surveys & Post-Test 1, Attitude 1, Reflection 1 Surveys \\
\hline
\end{tabular}

PBL related to electrical engineering usually includes a large complex design component that could only be executed in a lab. The magnitude of the PBL project is usually much larger than the traditional 'step-wise' instructions that students need to follow during discrete lab sessions. Students need to meet regularly in the lab until the PBL problem complies with the given specification(s) (Nedic et al., 2010). Resources were limited, but we had the privilege of having both a computer lab and an electronics lab available to us for most of the required allocated 8 sessions of 45 minutes per week. The computer lab was used for most of the time during normal lecturing. Whenever the PBL method was used, each pair in the group had to do research in the library, another computer lab or work in the electronics lab. Due to a lack of small venues the 11 student pairs were spread evenly during PBL 
sessions across the electronics lab with a capacity of 30 workstations. There was a sufficient space between the different student pairs with no interference between them. When students had to use the computer lab during practical classes the CG used the computers placed in the front rows while the EG used those at the back half. The researcher had to fulfil both the role as a facilitator to one group and a lecturer/lab-technician to the other. The evaluation between the CG and EG groups was different during the experiment (PBL problems versus 'step-wise' instructions), but the theoretical tests and examination had to be in common.

Both groups completed various pre- and post-tests, attitude- and reflection surveys, semester tests and an examination during the course. Some of these were done electronically, using Blackboard. All of the data were compared at the end of the course and the differences were analyzed.

The pre-test was done on paper during week 9 , but in order to ease the workload, all tests and surveys were done on Blackboard. All students, excluding those who were absent for the day, participated, resulting in a high response rate. The surveys related to the experiment were done in Week 14.

The 'Adaptive Learning Engagement in Science' questionnaire from (Velayutham, Aldridge, \& Fraser, 2011), composed of 32 attitude questions, was adapted to assess students' attitudes toward the Electronics I course. It contains three factors of attitudes and perceptions; (1) learning goal orientation, (2) task value, and (3) selfregulation. A five-point Likert scale was used to measure the level of agreement of the student with the statement, with a score of 5-Strongly Agree, 4-Agree, 3-Neutral, 2-Disagree, and 1-Strongly Disagree.

The National Council for Curriculum and Assessment (NCCA) (2011) key skills student reflection sheet, composed of 54 reflection questions was adapted to assess students' reflection toward the Electronics I course. It contains six factors of reflection; (1) information processing, (2) critical and creative thinking, (3) communicating, (4) working with others, (5) being personally effective, and (6) class experience. A five-point Likert scale was used to measure the level of agreement of the student with the statement, with a score of 5-Strongly Agree, 4-Agree, 3Neutral, 2-Disagree, and 1-Strongly Disagree. Four additional qualitative activities were included. (1) "Choose two of your favourite items above, where you have chosen a high score like 'Strongly Agree' and explain why you gave them a high score and describe in some detail what you did", (2) "What thing did you like the most?", (3) "So what was the main thing that you learned?", and (4) "Now what! - what skill would you like to develop more?"

The reliability of the surveys was evaluated by means of Cronbach's Alpha coefficient. The coefficient calculated from the data of all surveys was $\geq 0.8$, showing the reliability of the surveys. An independent $t$-test with a 95\% confidence interval was used to compare the mean scores between the EG and CG for each of the individual items as well as for the different factors within the attitude and reflection surveys of the experiment. Surveys are shown in Appendix 1 and 2.

\section{EXPERIMENTAL CONDITION - MIXED APPROACH OF ELECTRONICS 1}

Electronics 1 (ETRO1) covers the following topics/modules:

1. Instruments

2. Semiconductor theory

3. $\quad$ Diode theory

4. Diode characteristics

5. Diode applications

6. Bipolar junction transistor (BJT) theory

7. BJT characteristics

8. BJT applications

Most of the $1^{\text {st }}$ year students had very little or no prior knowledge about instruments, such as oscilloscopes, multimeters, bench power supplies, frequency generators and analog/digital trainers. The theory and its practical use was covered in the electronic lab using a hands-on approach where possible. 
The content of the semiconductor and diode theory is theoretically oriented and at the time of the research the traditional lecturing methods were used. Students were also introduced to Multisim, an electronic schematic capture and simulation program. Students had to work within their pre-allocated groups/pairs during the experiment. A prior experiment was done in a traditional way with all the instructions given to the students. They were required to compare simulated and real measurements via hand plotted graphs before plotting it using Excel. Most of them needed assistance with Excel. It was also the first time that the students had used the electronic 'Bread Board' (BB) to construct a circuit - a big learning experience for most of them. Figure 1 shows an example of an 'Electronic trainer unit' with a (white) BB containing a basic electronic circuit.

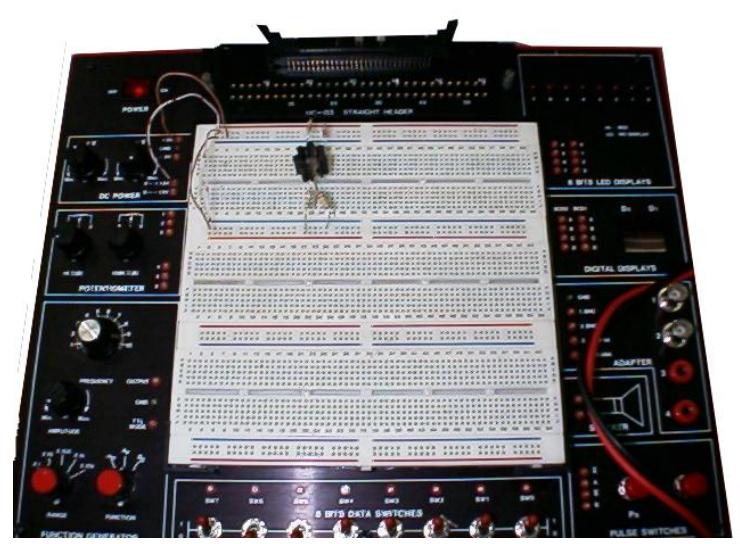

Figure 1. Electronic Trainer Unit With A Bread Board

The content of 'Diode Applications' lends itself towards problem-based project work, but all students had to participate in a pre-test to test the prior knowledge before continuing with the experiment. This and various other steps that followed are shown in Figure 2. Students from the EG were excluded from the lectures that related to 'full-wave bridge rectifiers', 'voltage regulators' and 'filters' since it was part of the experiment. After being introduces to the PBL procedure students had to solve a real-life problem, in this case a power supply that needs to fulfil a certain function. Collaborative learning was embedded in the PBL-model with the students being the primary focus of instruction, interacting with each other and working in groups on a real world problem.

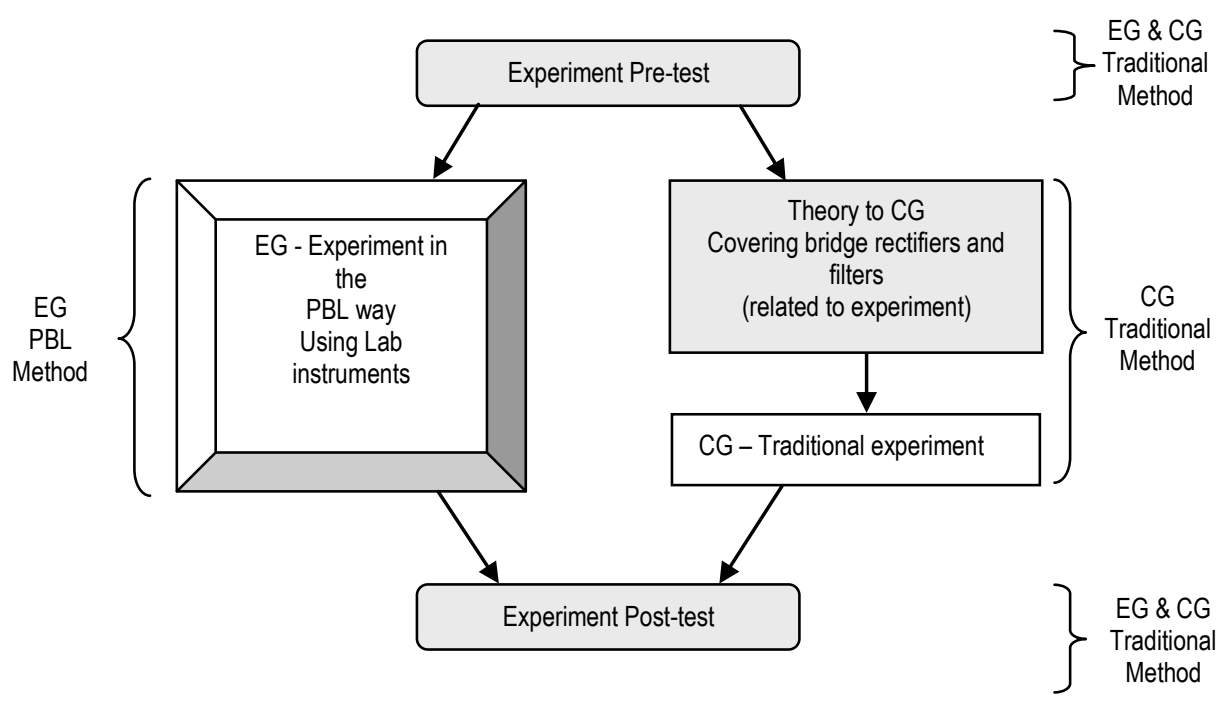

Figure 2. Illustration Of How The Experiment Was Conducted. 
The EG students were requested to solve the problem, following the operational definition of PBL according to Barrett, Mac Labhrainn, and Fallon (2005) - see Appendix 3.

The PBL procedure was as follows:

1st Small group meeting - PBL students met in their respective pairs and discussed the problem. Each student in the group had to use his/her own knowledge and experience and presume that they were personally asked to solve the problem/s. They needed to come up with a small number of hypotheses that were likely to explain and solve the problem and then divide the work to be done amongst the group members.

Individuals - They worked separately over the next 2 days to allow each member to independently carry out the research on how to design, develop, and test a suitable power supply.

2nd Small meeting - The pairs met again and drew conclusions on the nature of the problem and the best fit solutions given the information known.

Finally, each pair of students implemented the solutions, demonstrated the operation of the power supply, and submitted a report as to the solution and its consequences.

The EG was working on their problem while, the CG had to finish the theory classes before continuing with their traditional experiment. This caused the time-on-task to be similar for both groups during the experiment as indicated in Figure 2, but with a difference in the overall time spent on the theory and experiment as shown in Table 2. All students had to do a post-test after the experiment.

Table 2. Overall Time Spent On The Various Activities

\begin{tabular}{lcc}
\hline & \multicolumn{3}{c}{ Time Spent } \\
\cline { 2 - 4 } Activity & EG & CG \\
\hline Theory & $61 \%$ & $66 \%$ \\
Experiment & $31 \%$ & $26 \%$ \\
Tests and Surveys & $8 \%$ & $8 \%$ \\
\hline
\end{tabular}

\section{Power supply - Experiment for the PBL group}

Students in the PBL group had to solve a real-life problem while assuming that they were working for a real company. They had to develop a power supply that needed to comply with certain requirements, including supplying a regulated voltage to a variable load while the incoming supply from the electricity provider was unstable. Details of the problem are shown in Appendix 4.

The appropriate outcome based on the subject level, should be a power supply, using preferably a $16 \mathrm{~V}$ transformer with a full-wave bridge rectifier, a zener diode voltage regulator circuit and a capacitor as a filter. Most students followed this route, but some of them started with more advanced circuits, containing transistors and voltage regulators. Eventually they switched to the more basic circuits. Initially, students had problems in identifying the primary and secondary windings of a transformer and needed assistance. A variac was used to adjust the 'supply voltage' between $180 \mathrm{VAC}$ and $240 \mathrm{VAC}$ during the testing phase. The project was challenging to the students as it required them to regulate the output voltage for various loads and input voltages.

\section{RESULTS}

On completion of the experiment the presence of any significant difference between the EG and CG student's attitudes and reflections were checked using appropriate surveys. The pre- and post-test scores were also used to check the Learning Effects. 


\section{Attitude}

None of the factors, 'learning goal orientation', 'task value', or 'self-regulation' appeared significant during an independent-samples $t$-test. However, three from the thirty two individual items differed significantly as shown in Table 3. See Appendix 2 for all items related to attitude.

Table 3. Items Related To Attitude

\begin{tabular}{|c|c|c|c|c|c|c|c|c|}
\hline \multirow[b]{2}{*}{ Individual items } & \multicolumn{3}{|c|}{ EG } & \multicolumn{3}{|c|}{ CG } & \multirow[b]{2}{*}{$p$} & \multirow[b]{2}{*}{$t$} \\
\hline & $M$ & $S D$ & $n$ & $M$ & $S D$ & $n$ & & \\
\hline $\begin{array}{l}\text { In this Electronics } 1 \text { class, What I learn satisfies my } \\
\text { curiosity. }\end{array}$ & 4.06 & .998 & 18 & 3.45 & 1.191 & 20 & .050 & 1.688 \\
\hline In this Electronics 1 class, I am good at this subject. & 3.61 & .778 & 18 & 3.05 & 1.026 & 19 & .036 & 1.858 \\
\hline $\begin{array}{l}\text { In this Electronics } 1 \text { class, I concentrate so that I will } \\
\text { not miss important points }\end{array}$ & 4.61 & .502 & 18 & 4.30 & .470 & 20 & .028 & 1.973 \\
\hline
\end{tabular}

The 'sum scores' for the various factors as well as all factors combined, were also very similar. These results, although not overwhelming, tend to support Hypothesis 1 that the overall attitude will be more positive among students who participate in PBL activities compared to those in the lecturing mode.

\section{Reflection}

An independent-samples $t$-test was not significant for factors 1, 2, 5 and 6 (information processing, critical and creative thinking, being personally effective and class experience - see Appendix 1), but the mean values for the EG were still higher in all cases. Factors 3 and 4 (communicating and working with others) as well as various individual items related to the Likert-type scale questions of the reflection survey (significant $p \leq .05$ ) differed significantly during an independent-samples $t$-test with a preference towards PBL (EG) as shown in Table 4 . The $6^{\text {th }}$ item shows that students in the EG felt that they received less help, which confirms that the PBL condition was felt as one with a higher autonomy.

Table 4. Significant Individual And Categorized Items Related To Reflection During The Experiment

\begin{tabular}{lcc|cc|c|c}
\hline & $\mathbf{E G}(n=18)$ & \multicolumn{2}{c|}{$\mathbf{C G}(n=22)$} & \multicolumn{1}{c}{$\boldsymbol{t}$} \\
\cline { 2 - 5 } Individual questions & $\boldsymbol{M}$ & $\boldsymbol{S D}$ & $\boldsymbol{M}$ & $\boldsymbol{S D}$ & $\boldsymbol{p}$ \\
\hline I got information from different sources. & 4.61 & .502 & 3.77 & 1.1378 & .010 & 2.448 \\
I checked the reliability and credibility of different sources. & 4.17 & .707 & 3.68 & .945 & .040 & 1.801 \\
I expressed myself in a written Presentation. & 4.39 & .608 & 3.73 & .935 & .007 & 2.585 \\
I worked in pairs. & 4.78 & .548 & 4.18 & 1.097 & .022 & 2.097 \\
I worked in small groups. & 3.17 & 1.581 & 2.09 & 1.231 & .010 & 2.420 \\
I received help from my lecturer or lab technician. & 3.61 & 1.092 & 4.09 & .921 & .070 & -1.508 \\
\hline Factors & & & & & & \\
\hline Communication. & 3.82 & .485 & 3.50 & .481 & .045 & 2.072 \\
Working with others. & 4.11 & .465 & 3.80 & .380 & .036 & 2.178 \\
\hline
\end{tabular}

The results reflected in Table 4 support Hypothesis 2: that the amount of reflection is considered greater among the students who participated in PBL activities compared to those of the lecturing mode.

\section{Learning Effects}

Both the EG- and CG students did theory and a prior experiment in the traditional way. They had to do a pre-test before proceeding with the experiment itself. This pre-test was common for both groups and it contains both questions related to work already covered and also questions related to work that was covered during the experiment. An independent t-test revealed a significant difference in the means of pre-test marks, $\mathrm{EG}(M=30.5 \%$, $S D=16.05)$ and CG $(M=40.0 \%, S D=15.81), t(39)=-1.909, p<.032$. The $9.5 \%$ mean difference between the pre-test scores is significant at the level of 3.2\%; an indication that the EG entered the experiment with a lower prior knowledge. However, students were not selected based upon prior knowledge and it is not surprising that they were different in this respect. Selective examination questions were used 2 weeks after the post-test as a retention test. The analysis focuses on the differential effect due to the difference between the EG and CG. 
Table 5. Learning Effects Related To The Experiment

\begin{tabular}{|c|c|c|c|c|c|c|c|c|}
\hline \multirow[b]{2}{*}{ Item } & \multicolumn{3}{|c|}{ EG } & \multicolumn{3}{|c|}{ CG } & \multirow[b]{2}{*}{$p$} & \multirow[b]{2}{*}{$t$} \\
\hline & $M$ & $S D$ & $n$ & $M$ & $S D$ & $n$ & & \\
\hline $\begin{array}{l}\text { Short-term Learning-Effect } \\
\text { (Post-test - Pre-Test) }\end{array}$ & $33.0 \%$ & $36.8 \%$ & 17 & $28.2 \%$ & $29.0 \%$ & 18 & .336 & .428 \\
\hline $\begin{array}{l}\text { Long-term Learning-Effect } \\
\text { (Retention Test - Post-Test) }\end{array}$ & $-2.7 \%$ & $36.0 \%$ & 17 & $-4.0 \%$ & $42.3 \%$ & 19 & .461 & .097 \\
\hline
\end{tabular}

Independent t-tests were used to determine the initial level of both groups during the pre-test, and the effects of each of the types of instructional strategies on learner performance in the post-test, containing relevant near-transfer problems. Similar t-tests were also used to determine the learning effect. With EG $(M=33.032, S D=$ $36.840)$ and CG $(M=28.248, S D=29.032)$ the learning effect did not differ significantly, $t(33)=.428, p=.336$. This is in line with the results from a repeated measures Anova test of between-subjects effects that were additionally done, indicating no significant effect between the groups on learning effects $(F(1,32)=2.135, p=.154)$.

Table 5 shows that in terms of absolute values (33.032 vs. 28.248) the EG scored a higher learning effect and a lower decay (2.744 vs. 4.028). However as its differences did not reach the $5 \%$ level $(\alpha=.05)$, it cannot be concluded that these differences were significant.

\section{CONCLUSIONS}

A brief overview of the main findings from the research, in relation to the stated hypotheses for the research study, is presented below.

The Overall Attitude Towards The Study Will Be More Positive Among Students Who Participate In PBL Activities Compared To Those In The Lecturing Mode.

The statistical analysis of learner attitude levels supports Hypothesis 1 that the overall attitudes are more positive among students who participate in PBL activities compared to those in the lecturing mode (Table 3). These results suggest that PBL had a positive effect on the attitude of the EG students, giving them more self-confidence and making the topic more appealing. As their curiosity was satisfied, they had more confidence in themselves and they did not want to miss any important points. PBL obliges students to become more actively involved.

\section{The Amount Of Reflection Is Higher Among Students Who Participate In PBL Activities Compared To Those In The Lecturing Mode.}

Analysis of the data on reflection (Table 4) supports Hypothesis 2 that the amount of reflection is higher among the students who participate in PBL activities compared to those of the lecturing mode. The results suggest that the students in the EG condition learned how to search for information, make decisions and co-operate with their partners. All items, except for the $6^{\text {th }}$ one (Table 4), suggest that the students in the EG condition experienced a richer learning experience and a subsequent higher involvement in terms of presentation and collaboration. The perceived decline in teacher help to the PBL group is an indication that the students learned to become more independent in their learning and problem-solving, as expected from a student-centered classroom pedagogy.

Items 4, 5, 7 and 8 in Table 4 show that in the EG condition, they worked more in pairs and small groups although both the EG and CG were grouped in dyads. The PBL method stipulates that each student in a group should explore a certain area within a project (experiment) and make a specific contribution. In contrast, students who do experiments in a traditional way usually work together in a group, and there is a less-articulated role for an individual. This might cause some group members not to participate but to rely on the partner to do the experiment instead. The CG students had to complete various tables and graphs on the hand-out material. They need more teacher assistance with these $\left(6^{\text {th }}\right.$ item of Table 4$)$ as expected since they adhere to the teacher-centered lecturing mode pedagogy. 


\section{Retention And Near Transfer Skills Will Be Higher Among Students Who Participate In PBL Activities Compared To Those In The Lecturing Mode.}

The pre-test, post-test and retention tests reported in this research study were focused on solving neartransfer problems. The short-term learning effect for the EG was $4.78 \%$ higher than the CG. The EG also outscored the CG by $1.28 \%$ during the long-term learning effect (see Table 5). These results suggest that the PBL method increased near transfer skills more than the traditional lecturing method. However, it is not significant and thus it does not reach the support level for Hypothesis 3.

\section{DISCUSSION}

Recent research into the effectiveness of PBL as an educational model indicates that as in this experiment, the PBL condition could not demonstrate its value in terms of higher learning outcomes. However, it shows a slightly higher effect on skills for problem-solving and longer-term retention. This is in accordance with the outcomes of earlier meta-studies (Dochy, Segers, Van den Bossche, \& Gijbels, 2003; Perrenet, Bouhuijs, \& Smits, 2000).

PBL requires students to activate prior knowledge and problem-solving skills and thus anticipate real-life situations once they are employed. One should, therefore, ask if it is fair to evaluate PBL effects through traditional examination methods. It can be expected that PBL students will achieve substantially higher results during a practical examination where a real-life problem needs to be solved. An outcome-based evaluation of skills rather than knowledge-based might be more suitable to evaluate the gained PBL effects and the Aalborg model of individual judgement in a team-based exam instead of traditional exams is suggested.

\section{Implications and further Research}

Students in the PBL condition became remarkably more responsible in making a success of their studies. Their curiosity was satisfied, they had to think more and what they had learned was of practical value to them. It is encouraging to note that the students remained motivated during the PBL activities with some testifying to the improvement in their self-confidence and sincerity towards their studies due to the active involvement required by PBL. It is expected that students who followed the PBL method should work easier in a team when employed, similar to the graduates from the Aalborg University as reported by Dahms and Stentoft (2008).

Students indicate the following from the qualitative data of the reflection survey:

- $\quad$ PBL group - They enjoyed the 'practical' part the most and indicated that they had mostly learnt how to 'design' an electronic circuit.

- $\quad$ The traditional group - enjoyed building a circuit practically and learning from the mistakes they made. They have mostly learnt about the electronic components used within the given circuit but not any design principles.

The traditional group only followed the instructions from the hand-outs during experiments. It was therefore no surprise to find that the attitude of the PBL group was significantly more positive according to the statistical analysis. It was possible for the experimenter to act as a lecturer, lab technician and facilitator and vice versa as required within the existing facilities of WSU, mainly because of the low student numbers and because the students worked in pairs. Lecturers who would like to mix PBL and traditional lectures in the future can follow the steps as shown in Appendix 3. PBL requires individual groups to meet in various dedicated small venues, especially if there are three or more in a group. PBL is also more time consuming, in particular when it is done for the very first time. It is not so easy to alter the pace due to the student-centred classroom strategy of PBL and sufficient time should be available to deal with problem-solving and project work as indicated by Sahin (2010). Care should also be taken during the problem design so that such designs match real life situations and here the involvement of industry might be valuable. 


\section{Recommendations}

The learner's mind-set in terms of interest (curiosity), attitude and learning approach should be improved and the retention of fundamental technical skills should be prolonged. All of these are highly valued by employers, resulting in better job opportunities for our students.

The following items might be considered during further research: using a method other than the random selection process to ensure that the EG and CG have similar prior knowledge. Dyads should be evaluated separately during experiments and sufficient time should be allowed for group presentations. Student evaluations should also include the application of far transfer skills.

This study only dealt with Electronics 1 and the outcomes were promising when the traditional and PBL methods were mixed. Institutions of higher learning who still offer engineering courses in the traditional way should consider promoting the use of the PBL method in at least one experiment for each of the major subjects across the engineering spectrum. Participating lecturers can then be trained in the use of PBL before implementation and dedicated facilitators could also be considered. The library and internet facilities will be used more frequently when PBL is used as a learning method and future library planning should included addressing this opportunity. A research topic for future research could focus on determining the overall impact that PBL has on graduates. The affect of PBL should also be tested on the 'under prepared' students who usually enter the university in the 'extended stream'. These students have a year, instead of a semester, to complete a subject such as Electronics 1, and PBL could be used prior to the lecture mode, or followed after the lecture mode to improve their skills, critical thinking and attitudes. Positive results can lead to a progressive increment in the use of PBL.

Finally, according to Dochy et al. (2003), the advantage of PBL above traditional lecturing is the significant improvement in the student's skills development without sacrificing knowledge attainment: and this study may be a step in that direction.

\section{AUTHOR INFORMATION}

Mr. J.M. Podges - a senior lecturer at Walter Sisulu University (South Africa), interests is electronics and education. Completed matric/grade 12 in 1978, studied at Tswane University of Technology and continued his masters studies at Nelson Mandela Metro pole University (NMMU). He developed a provisional patent system that allow users to do experiments remotely via an Internet enabled PC. He is presently busy with his PhD studies, related to PBL. His supervisorS are Dr. Piet and Dr. Koos Winnips. The promoter is Dr. Wouter van Joolingen. Email: podgesm@sainet.co.za (contact author)

Dr. Piet Kommers - associate professor in the University of Twente. Interest is media, learning and visual communication. His Master study formulated algorithms for adaptive learning. His PhD study questioned how conceptual representations may support the cognitive integration in learning. He was Scientific Director of NATO Advanced Research Workshop. From 1990 until now he was increasingly involved as partner and coordinator in European research projects in media based and continuous learning. His role in initiating higher education in Eastern Europe led to his UNESCO chair, followed by the award of honorary doctor by Capital Normal University in Beijing in 2000. E-mail: kommers@edte.utwente.nl

Dr. J.C. (Koos) Winnips - advisor ICT and Education at University of Groningen. Particular interest in innovation of electronic learning environments, and support of lecturers. He was a researcher, lecturer and later advisor of ICT in Education. Research on finding ways for efficient support of learning online (scaffolding). As advisor supporting innovation in university teaching and learning. Current projects include using wiki's in education, research driven education and interaction in large lectures using smartphones. Project manager for a number of innovation projects, covering topics in mathematics remediation, open source, streaming lecture recordings, and action learning. E-mail: koos.winnips@rug.nl

Dr. Wouter van Joolingen - Specializes in science education. Having a background in physics and a PhD in Educational Research the natural focus is on Science Education. The main goals of his work is to support the 
learning of science in such a way that learners can become flexible thinkers in science and have a realistic image of the scientific aspects of the world.

Specialties: Educational Research, Design of computer-based learning environments, Computer Simulation, Modeling, Teaching E-mail: W.R.vanJoolingen@uu.nl

\section{ACKNOWLEDGEMENTS}

The authors acknowledge contributions of Nuffic (NPT ZAF 237 / 267), participating students, and permission from the faculty of Science, Engineering, and Technology (FSET) at WSU to publish this study.

\section{REFERENCES}

1. Albanese, M. A., \& Mitchell, S. (1993). Problem-based learning: a review of literature on its outcomes and implementation issues. Academic Medicine, 68, 52-81.

2. Barrett, T., Mac Labhrainn, M., I, \& Fallon, H. (2005). Handbook of Enquiry \& Problem Based Learning. Galway: CELT. Retrieved from http://www.aishe.org/readings/2005-2/chapter2.pdf

3. Bethlehem, P. A. (1997). National Association of Colleges and Employers. Job Outlook 98. from http://www.gamesover.org/new career/transferable skills

4. Boud, P., \& Feletti, G. (1997). The Challenge of Problem-based Learning (Vol. 2nd edition). London: Kogan Page.

5. Bridges, E. M., \& Hallinger, P. (1991). Problem-based learning in medical and managerial education. Retrieved from http://academicjournals.org/ijps/PDF/pdf2010/Jun/Sel\%C3\%A7uk.pdf

6. Case, J. M. (2011). Knowledge matters: interrogating the curriculum debate in engineering using the sociology of knowledge. Journal of Education, 51, 73-92.

7. Dahms, M., \& Stentoft, D. (2008). Does Africa need Problem Based Learning? - Educational Change in Engineering Education. Paper presented at the American Society of Engineering Education (ASEE) Global Colloquium, Cape Town, South Africa. Retrieved from http://vbn.aau.dk/files/16599470/Does_Africa_need_PBL.pdf

8. de Graaff, E., \& Kolmos, A. (2003). Characteristics of Problem-Based Learning. International Journal of Engineering Education, 19(5), 657-662.

9. Dochy, F., Segers, M., Van den Bossche, P., \& Gijbels, D. (2003). Effects of Problem-Based Learning: A Meta-Analysis. Learning and Instruction, 13(5), 553-568.

10. Dusick, D. M. (1998). What social cognitive factors influence faculty members' use of computers for teaching? A literature review. Journal of Research on Computing in Education, 31(2), 123-137.

11. Erasmus, B. J., Loedolff, P. v. Z., Mda, T. V., \& Nel, P. S. (2006). Managing training and development in South Africa (5 ed.). Southern Africa: Oxford University Press.

12. Grabinger, S., Dunlap, J. C., \& Duffield, J. A. (1995). Rich environments for active learning in action: problem-based learning. Association for Learning Technology Journal, 5(2), 5-17.

13. Griesel, H., \& Parker, B. (2009). A baseline study on South African graduates from the perspective of employers - Graduate Attributes. South Africa: Higher Education South Africa \& The South African Qualifications Authority. Retrieved from http://www.saqa.org.za/docs/pubs/general/graduate attributes.pdf.

14. Hwang, S. Y., \& Kim, M. J. (2006). A comparison of problem-based learning and lecture-based learning in an adult health nursing course. Nurse Education Today, 26, 315-321. Retrieved from http://www1.ju.edu.jo/ecourse/mahmad/A\%20comparison\%20of\%20problembased $\% 20$ learning $\% 20$ and $\% 20$ lecturebased\%20learning\%20in\%20an\%20adult\%20health\%20nursing\%20course.pdf

15. Kitogo, A. S. (2011). How competent are Tanzanian graduates? . Retrieved 28/11/2011, from http://varsitycollegetz.ning.com/profiles/blogs/how-competent-are-tanzanian-graduates

16. Kolmos, A., de Graaff, E., \& DU, X. (2009). Diversity of PBL - PBL Learning Principles and Modules. In X. DU, E. de Graaff \& A. Kolmos (Eds.), Research on PBL Practice in Engineering Education (pp. 9-21). Rotterdam: Sense Publishers. 
17. Kolmos, A., Fink, K. F., \& Krogh, L. (2006). The Aalborg PBL model-Progress, Diversity and Challenges Vol. 1. (pp. 393). Retrieved from http://www.bog-ide.dk/productsamples/9788773079119.pdf

18. National Council for Curriculum and Assessment (NCCA). (2011). NCCA key skills student reflection sheet. Retrieved 17/10/2010, from http://www.ncca.ie/en/Curriculum_and_Assessment/PostPrimary_Education/Senior_Cycle/Key_skills_reflection_tools/Key_Skills_Reflection_Tools.html

19. Nedic, Z., Nafalski, A., \& Machotka, J. (2010). Motivational project-based laboratory for a common first year electrical engineering course. European Journal of Engineering Education, 35(4), 379-392.

20. O' Kelly, J. (2005). Designing A Hybrid Problem-Based Learning (PBL) Course: A Case Study of First Year Computer Science in Nui, Maynooth. Handbook of Enquiry and Problem-based Learning. Irish Case Studies and International Perspectives. Retrieved 05/10/2010, from http://www.aishe.org/readings/20052/chapter5.pdf

21. Ornstein, A. C., \& Hunkins, F. P. (1993). Curriculum: Foundations, Principles, and Theory. Ontario: Pearson Education Canada.

22. Perrenet, J. C., Bouhuijs, P. A. J., \& Smits, J. G. M. M. (2000). The suitability of problem-based learning for engineering education: Theory and practice. Teaching in Higher Education, 5(3), 345-358.

23. Pincus, K. V. (1995). Introductory accounting: changing the first course. New Directions for Teaching and Learning, 1995(61), 89-98. Retrieved from http://academicjournals.org/ijps/PDF/pdf2010/Jun/Sel\%C3\%A7uk.pdf doi:10.1002/tl.37219956112

24. Prince, M. J. (2004). Does active learning work? A review of the research. Journal of Engineering Education, 93(3), 223-231.

25. Sahin, M. (2010). The impact of problem-based learning on engineering students' beliefs about physics and conceptual understanding of energy and momentum. European Journal of Engineering Education, 35(5), 519-537.

26. Savin-Baden, M. (2007). Challenging Models and Perspectives of Problem-Based Learning in Kolmos, A. de Graaff, E. \& Du, X.: Diversity of PBL - PBL Learning Principles and Models. Retrieved from https://www.sensepublishers.com/media/891-research-on-pbl-practice-in-engineering-education.pdf

27. Schmidt, H. G., Lipkin, M., de Vries, M. W., \& Greep, J. M. (1989). New Directions for Medical Education: Problem-based learning and community oriented medical education (1 edition ed.). New York: Springer-Verlag.

28. Schön, D. (1983). The reflective practitioner. New York: Basic Books.

29. Taylor, N. (2008). What's Wrong with South African Schools? What's Working in School Development. from http://jet.org.za/events/conferences/What\%20works\%20in\%20school\%20development/Papers/Taylor\%20 Whats\%20wrong\%20with\%20SA\%20schools\%20JET\%20Schools\%20Conf\%20final.pdf

30. Velayutham, S., Aldridge, J., \& Fraser, B. (2011). Development and Validation of an Instrument to Measure Students Motivation and Self-Regulation in Science Learning. International Journal of Science Education, 33(15), 2159-2179. doi: 10.1080/09500693.2010.541529

31. Waters, R., \& McCracken, M. (1997). Assessment and Evaluation in Problem-Based Learning. Retrieved from http://w.fie-conference.org/fie97/papers/1454.pdf

32. Whitehead, A. N. (1929). The Aims of Education and Other Essays (in Grabinger, S., Dunlap, J.C., and Duffield, J.A. Rich environments for active learning in action: problem-based learning). New York: Macmillan.

33. Woods, D. R. (1996). Problem-based Learning: How to Gain the Most from PBL. Canada: Waterdown.

34. Yusof, K. M., Hassan, S. A. H. S., \& Tasir, Z. (2007). Inducting First Year Engineering Students into Problem-Based Learning. Singapore: Centre for Educational Development Republic Polytechnic. 


\section{APPENDICES}

\section{Appendix 1}

Reflection survey adopted from National Council for Curriculum and Assessment (NCCA) (2011).

\section{Information Processing}

I got information from different sources.

I had to make my own notes in my own words.

I had to present information in different ways like tables and graphs.

I had to summarize the most important points.

I had to choose how to present information most effectively.

I used Information and Communication Technology (ICT) such as computer, video clips or digital camera.

\section{Critical and Creative thinking}

I had to look carefully to find information.

I had to find the pattern in information.

I identified similarities and differences.

I asked critical questions.

I used critical thinking to understand problems.

I tried to see things from different angles.

I looked at different ways of solving a problem.

I looked at the results and reached my own conclusion.

I put forward my opinion and/or ideas.

I used my imagination.

I reflect critically on the ideas raised during the experiment when the class is over.

\section{Communicating}

I examined the experiment carefully, looking at it from different perspectives.

I checked the reliability and credibility of different sources.

I gave my own opinion.

I listened carefully to what others had to say.

I asked questions and responded to what others had to say.

I expressed myself in a variety of ways:

- $\quad$ Art

- Computer based design and Graphics

- Oral Presentation

- Written Presentation

- $\quad$ Other (Specify)

Working with others

I worked in pairs.

I worked in small groups.

I cooperated with my partner/group member to agree how we would get the task done.

I played my part within the group and took my share of responsibility.

I communicated my ideas.

I listened to the ideas of others and showed respect for other people.

I helped someone else in doing his/her work.

I made helpful suggestions about ways forward.

I helped resolve conflict/disagreement.

I kept to our agreed task and deadline. 
Being personally effective

I set out my own objectives and knew what I want to achieve.

I made a plan to help me reach my target.

I went looking for help and resources that I needed to help me.

I received help and feedback from my fellow students.

I received help from my lecturer or lab technician.

I used that feedback to help me to plan my next action and progress further.

I keep up with the requirements even when it was difficult.

I made mistakes and learn from them.

I tried different ways/solutions until I was satisfied that I had found the best.

I kept to my agreed task and deadline.

I fell good about what I have done.

I enjoyed the experiment.

Class experience

I am confident about Electronics I.

When it is not working out, I give up.

I like it when we are doing simulations in the class.

I like it when we are doing the activities in the class.

\section{Appendix 2}

Attitude survey examples - Velayutham et al. (2011).

Learning goal orientation

In this Electronics 1 class:

One of my goals is to learn as much as I can.

One of my goals is to learn new Electronics 1 contents.

One of my goals is to master new Electronics 1 skills.

It is important that I understand my work.

It is important for me to learn the Electronics 1 content that is taught.

It is important to me that I improve my Electronics 1 skills.

It is important that I understand what is being taught to me.

Understanding Electronics 1 ideas is important to me.

Task value

In this Electronics 1 class:

What I learn can be used in my daily life.

What I learn is interesting.

What I learn is useful for me to know.

What I learn is helpful to me.

What I learn is relevant to me.

What I learn is of practical value.

What I learn satisfies my curiosity.

What I learn encourages me to think.

Self-efficacy

In this Electronics 1 class:

I can master the skills that are taught.

I can figure out how to do difficult work.

Even if the Electronics 1 work is hard, I can learn it.

I can complete difficult work if I try.

I will receive good grades.

I can learn the work we do. 
I can understand the contents taught.

I am good at this subject.

Self-regulation

In this Electronics 1 class:

Even when tasks are uninteresting, I keep working.

I work hard even if I do not like what I am doing.

I continue working even if there are better things to do.

I concentrate so that I will not miss important points.

I finish my work and assignments on time.

I do not give up even when the work is difficult.

I concentrate in class.

I keep working until I finish what I am supposed to do.

Appendix 3 - Operational definition of PBL according to Barrett et al. (2005).

1. $\quad$ First students are presented with a problem.

2. Students discuss the problem in a small group PBL tutorial. They clarify the facts of the case. They define what the problem is. They brainstorm ideas based on their prior knowledge. They identify what they need to learn to work on the problem, i.e. what they do not know (learning issues). They reason through the problem. They specify an action plan for working on the problem.

3. Students engage in independent study on their learning issues outside the tutorial. This can include: library, databases, the web, resource people and observations.

4. They come back to the PBL tutorial(s) sharing information, peer teaching and working together on the problem.

5. They present their solution to the problem.

6. They review what they have learned from working on the problem. All who participated in the process engage in self, peer and tutor review of the PBL process and reflections on each person's contribution to that process.

\section{Appendix 4 - Power Supply Problem}

Assume that you are working for WSU Electronics. They have developed a wireless alarm system that operates from a $12 \mathrm{~V}$ battery and have sold thousands. Some of the customers are complaining that the battery life for this system is very short and they would prefer that it rather operates from a $220 \mathrm{~V} 50 \mathrm{~Hz}$ supply. Your boss came to you (and your group mate) and asked you to design, develop and test a suitable power supply for this system. He warned you that the alarm system is very sensitive to voltage changes, but it should work fine if the voltage remains between 11.9 and 12.2 V. He also mentioned that the 220VAC from some of the Electricity Suppliers can go as low as $180 \mathrm{VAC}$ and as high as $240 \mathrm{VAC}$ from time to time, usually for small periods. The alarm system uses at least 12 $\mathrm{mA}$ when passive, but it can go as high as $51 \mathrm{~mA}$ when the siren is activated. Thousands of these power supplies are expected to be sold and you are requested to make the system as cheap as possible in an effort to maximise the profit. WSU Electronics are manufacturing various low cost transformers at different power ratings, but they cannot make the 'center-tapped' type. Your boss insisted that you should use one of the transformers from WSU Electronics in your design. The following transformers are available: $8 \mathrm{~V}, 16 \mathrm{~V}, 19 \mathrm{~V}$, and $38 \mathrm{~V}$. 
NOTES 